\title{
Leiomyoma of the anterior vaginal wall: a rare
}

\section{case}

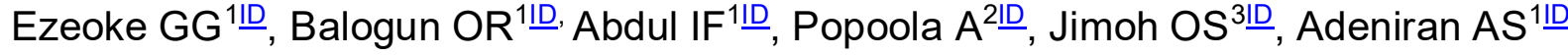 \\ ${ }^{1}$ Department of Obstetrics and Gynecology, University of llorin Teaching Hospital, Ilorin, Nigeria \\ ${ }^{2}$ Department of Surgery, University of Ilorin Teaching Hospital, Ilorin, Nigeria \\ ${ }^{3}$ Department of Obstetrics and Gynecology, Federal Medical Centre, Idi-Aba, Abeokuta, Nigeria \\ ID: Orcid ID
}

Submitted: $4^{\text {th }}$ August 2021

Accepted: $11^{\text {th }}$ September 2021

Published: $30^{\text {th }}$ December 2021

\begin{abstract}
Background: Leiomyoma is a benign smooth muscle mesenchymal tumor, usually of uterine origin but may rarely develop in the vaginal walls.

Case presentation: A case of 40 -year-old para 5+0 woman with anterior vaginal wall leiomyoma is reported. The presentation mimics that of uterovaginal prolapse and hence presents a diagnostic challenge. The unusual appearance of the protrusion, failure to reduce at any time even while lying down, and complete absence of urinary symptoms raised the suspicion of a rare case. The diagnosis was made through examination under anesthesia, cystoscopy, and biopsy. Histological examination of the biopsy specimen confirmed vaginal wall leiomyoma. The patient had complete excision of the mass without any complications.

Discussion and Conclusion: Vaginal wall leiomyoma is a rare benign vaginal lesion that can easily be misdiagnosed. Diagnosis involves critical clinical evaluation, especially during pelvic examinations. Any vaginal protrusion should be approached with a high index of suspicion, especially in patients of reproductive age.
\end{abstract}

Keywords: Leiomyoma, Cystoscopy, Biopsy, Vaginal Wall, Utero-Vaginal Prolapse

\section{Background}

Leiomyoma is a benign neoplasm of the smooth muscle, usually of the uterus but can occur in other sites like the cervix, broad ligament, and rarely vaginal walls. The tumor consists of smooth muscle cells in combination with varying amounts of fibrous tissue. The occurrence of this tumor in the anterior vaginal wall is uncommon.

\section{Case presentation}

Mrs. AD, a 40 -year-old, para5 ${ }^{+0}$ petty trader presented in our clinic with a history of protrusion of a mass per vagina of 3 months' duration. The protrusion was painless and said to be fleshy, not reducible at any time, and not increasing in size. There was associated watery vaginal discharge but no bleeding per vagina. There was no history of any urinary symptoms, no straining while defecating and she has not been carrying heavy objects. There was no history of abdominal swelling and abdominal pain, however, she complained of low back pain. Mrs. AD had stopped sexual activities since the onset of the symptoms. Her cycle had been regular; she bleeds for 5days in a 28-30 days' cycle. Her last Childbirth was 8 years before presenting and all her 5 parous experiences were hospitalsupervised deliveries with no history of prolonged labor or perineal injury during the deliveries.

Examination at the presentation revealed an anxious-looking woman who was not pale and afebrile. Her Body Mass Index was $26.2 \mathrm{kgm}^{-2}$, her pulse rate was 82 beats per minute and her blood pressure was $100 / 70 \mathrm{mmHg}$. There was no mass palpable on abdominal examination. 
Pelvic examination revealed a hyperaemic mass covered with slough protruding outside the introitus. The mass measured $10 \mathrm{~cm}$ by $10 \mathrm{~cm}$, firm in consistency and originating from the anterior wall of the vagina. The anterior vaginal wall was edematous. The mass was not tender and there was no active bleeding on contact. There was no further protrusion of the mass on the Valsalva maneuver and no demonstrable urinary incontinence. It was also not reducible. The urethral meatus was visible and had a tiny fleshy tag at 1'0' clock position. The cervix was in its anatomical position, firm and os were patulous. The posterior vaginal wall was normal, the uterus was not bulky, the adnexa was free and the pouch of Douglas was empty. There were no abnormal findings on rectal examinations.
An initial diagnosis of vaginal wall mass probably infected vaginal wall cyst with differentials of vaginal cancer and bladder cancer was made.

Mrs. AD was commenced on broad-spectrum antibiotics and the mass was dressed daily with gauze soaked in normal saline. The urologist was invited to review the patient and made an assessment of the suspected bladder tumor. A second opinion by another gynecologist a few days after admission, when the edema has markedly subsided, raised the possibility of vaginal wall leiomyoma.

The full blood count showed a mild elevation in white blood cell count but the packed cell volume, serum electrolyte, urea, and creatinine as well as the urine analysis were all normal. Ultrasound Scanning showed no abnormality as the uterus was normal in size and in its anatomical position.

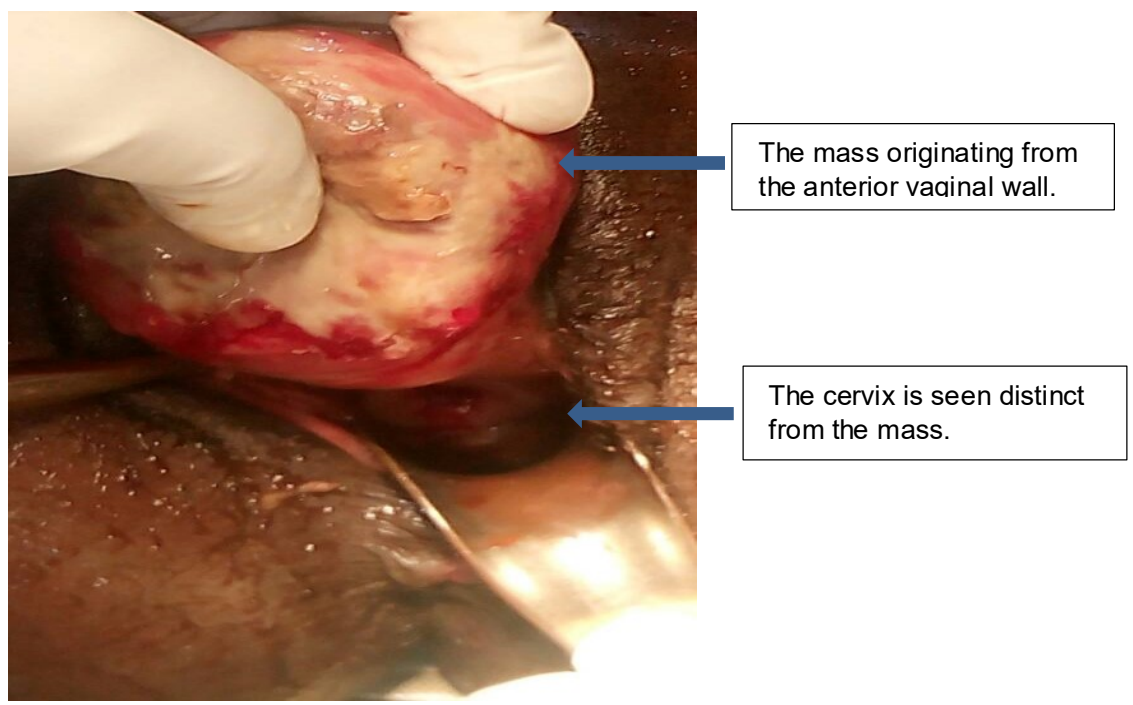

Figure 1: The vaginal mass during an examination

The patient had an examination under anesthesia, cystoscopy, and incisional biopsy. The cystoscopy findings showed prolapsed small fleshy tissue from the urethral meatus, hyperaemic urethral mucosa, and a patchy granular mucosa of the bladder from the trigone to the inferolateral wall on the left. There was no indentation of the bladder wall. A cystoscopic biopsy of the bladder mucosa was taken. The vaginal examination findings revealed an anterior vaginal wall mass measuring $10 \mathrm{~cm}$ by $10 \mathrm{~cm}$ and firm to touch, protruding from the introitus. The edema and slough noted at admission had markedly reduced. Bimanual examination of the pelvic structure and rectal examination did not reveal any abnormality. An incisional biopsy of the mass was taken and the urethral tag was excised.

Histology report of the urethral biopsy revealed chronic suppurative inflammation while the bladder mucosa biopsy showed cystitis glandularis. However, the vaginal wall mass biopsy showed extensive mucosa ulceration with proliferating fascicle of spindle-shaped smooth muscle cells but no mitotic figures or necrosis was seen. The conclusion of the report showed the mass to be a vaginal leiomyoma. 


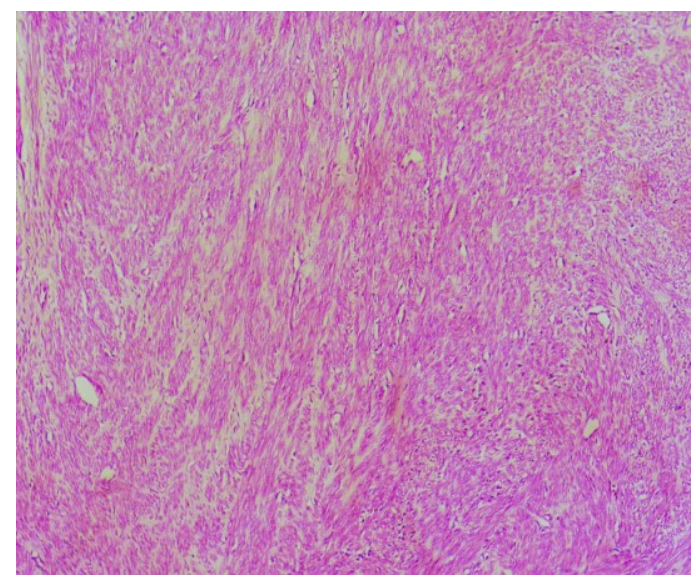

Figure 2: Microscopic image of the lesion showing spindle-shaped smooth muscle cells with eosinophilic cytoplasm.

Subsequently, she had excision of the anterior vaginal wall fibroid through the vaginal route under subarachnoid block. The urethra was catheterized, a circumferential incision was made at the base of the mass down to its capsule and the mass was removed via further sharp and blunt dissections. The resultant defect was closed with interrupted stitches using vicryl 1 suture in double layers and there was minimal bleeding intra-operatively.

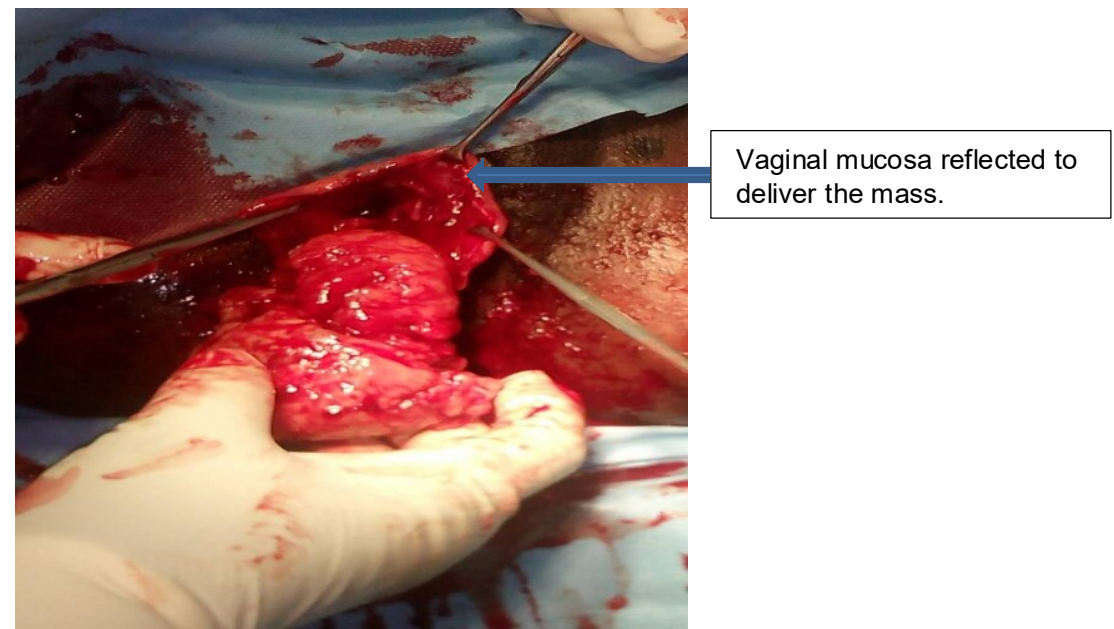

Figure 3: The vaginal mass (leiomyoma) about to be completely excised from the vaginal wall

Mrs. $A D$ was continued on analgesia and antibiotics and was discharged 5 days after the surgery. The follow-up visit at the clinic was uneventful.

\section{Discussion and conclusion}

Leiomyoma of the vagina is a very rare primary tumor of the vagina with only about 300 reported cases worldwide (1) and it constitutes about $4.5 \%$ of all solid vaginal tumors (2). The commonest site of vaginal leiomyoma is the anterior wall and occasionally in the lateral wall and vulvar area (3). The actual etiology is still unknown but, some researchers, however, believed that it may be due to residual embryonic vascular tissue and smooth muscle fibers in the vaginal wall (4). It is mostly seen in women between the age of 35 to 50 years but, it has been reported in patients of pubertal age to the age of 71 years (5). Mrs. A.D had an anterior vaginal wall fibroid and is 40years old thus fits the category of women in whom this rare tumor can occur.

Vaginal leiomyoma is usually firm but, may undergo degeneration to become soft. The variation in the consistency from firm to soft makes diagnosis more difficult $(3,6)$. It is usually asymptomatic until it reaches a larger size $(4,7)$. Symptoms often vary depending on the location of the tumor and may include genital organ prolapse, dyspareunia, vaginal discomfort, 
vaginal bleeding, urinary symptoms, lower abdominal pains, and low back pain $(4,7,8)$.

A meticulous vaginal examination should be employed in the diagnosis of vaginal masses to differentiate various masses that can arise in the vagina. The differential diagnoses of vaginal leiomyoma include; cystocele, Gartner's duct cyst, Skene's duct cyst, Mullerian remnant cyst, epithelial inclusion cyst, ectopic ureterocoele, leiomyosarcoma, urethral, and bladder malignancy $(2,8,9)$. The initial diagnosis for this patient was an infected vaginal wall cyst and a bladder tumor was also a differential. A high index of suspicion is necessary for the clinical diagnosis of this rare vaginal wall tumor.

Examination under anesthesia with biopsy of the mass and cystoscopy are very vital in arriving at a definitive diagnosis of vaginal leiomyoma as demonstrated in this case.

Cystoscopy helps rule out bladder tumors as it offers direct visualization of the bladder mucosa. It usually shows distorted bladder walls in cases of bladder tumors (10). The similarity of anterior vaginal wall leiomyoma and bladder tumor makes cystoscopy an extremely important procedure as was done for Mrs. AD. Hysteroscopy could be done in some cases to further exclude the likelihood of the mass originating from the endometrium especially in instances where the diagnosis is problematic (10). This was not done for Mrs. AD because the cervical os was seen and distinct from the mass.

A vaginal approach is the most preferred route of removal for average-sized tumors while the abdominoperineal approach is usually recommended for the larger masses that may extend into the pelvis $(8,11)$. It is very important to do a biopsy to rule out malignancy before proceeding on surgical excision. Recurrent vaginal leiomyoma is extremely rare and only a few cases have been reported (12). Mrs. AD was properly counseled on this uncommon complication.

Vaginal leiomyoma is an uncommon condition and may be misdiagnosed as uterovaginal prolapse or even bladder neoplasm especially when it is located in the anterior vaginal wall. The diagnostic dilemma could be easily resolved with proper examination preferably under anesthesia, biopsy, cystoscopy, and histological confirmation. We have documented this rare condition to contribute to available literature and raise awareness locally, nationally, and internationally. It is pertinent for clinicians to keep in mind some rare vaginal tumors while evaluating vaginal masses and evaluation should not only be tailored towards common lesions.

\section{Declarations}

\section{Ethics consideration}

Written informed consent for publication was obtained from the patient whose management is being reported.

\section{Consent for publication}

The authors hereby give consent for the publication of this work under the Creative Commons CC Attribution. Non-commercial 4.0 license.

\section{Availability of data and materials}

All data generated or analyzed in this study are included in this article and are available on request.

\section{Competing interests}

The authors declare no competing interest in the publication of this case report.

\section{Funding}

The authors did not receive any financial support for this publication.

\section{Contributions of authors}

History taking: JOS/EGG/AAS

Ward rounds/review JOS/EGG/AAS/AIF/PA

Surgeries $\quad E G G / B O R / J O S / P A$

Surgical findings interpretation:

EGG/BOR/AIF/PA/JOS/AAS

Writing of case report: EGG/JOS/AAS

Editing of case report: PA/AAS/BOR/AIF

Proof-reading and revision of case report for final submission: JOS/EGG/AAS/PA/AIF/BOR

\section{Acknowledgments}

Nil

\section{References}

1. Young SB, Rose PG, Reuter KL. Vaginal fibromyomata: two cases with preoperative assessment, resection, and reconstruction. Obstetrics and gynecology. 1991 Nov 1;78(5 Pt 2):972-4.

2. Singh R, Yadav $P$, Kaur $H$. Vaginal leiomyoma: a rare presentation. J South Asian Feder Obst Gynaecol. 2014 May;6(2):112-3.

3. Wethmar EI, D Mouton A, Dreyer G. Vaginal leiomyoma presenting as a lateral vaginal wall mass. Southern African Journal of Gynaecological Oncology. 2017 Jan 
2;9(1):16-8.

https://doi.org/10.1080/20742835.2017.1314 630

4. Dane C, Rustemoglu Y, Kiray M, Ozkuvanci U, Tatar Z, Dane B. Vaginal leiomyoma in pregnancy presenting as a prolapsed vaginal mass. Hong Kong Med J. 2012 Dec 1;18(6):533-.

5. Imai $A$, Furui $T$, Hatano $Y$, Suzuki M, Suzuki N, Goshima S. Leiomyoma and rhabdomyoma of the vagina Vaginal myoma. Journal of Obstetrics and Gynaecology. 2008 Jan 1;28(6):563-6. https://doi.org/10.1080/01443610802310333

6. Oruç S, Karaer O, Kurtul O. Coexistence of a prolapsed, pedunculated cervical myoma and pregnancy complications: a case report. The Journal of reproductive medicine. 2004 Jul 1;49(7):575-7.

7. Goyal LD, Kaur H, Kaur K, Kaur S. An unusual case of vaginal myoma presenting with postmenopausal bleeding. Journal of Family and Reproductive Health. 2013:103-4.

8. Koranne PS, Raut D, Wahane A, Uike P. A rare case of anterior vaginal wall leiomyoma.
The Journal of Obstetrics and Gynecology of India. $\quad 2015 \quad$ Apr 1;65(2):129-31. https://doi.org/10.1007/s13224-014-0610-8

9. Perugia G, Ciccariello M, Pirolli F, Chinazzi A, Teodonio S, Borgoni G, Croce F, Liberti M. Paraurethral leiomyoma. Urology. 2012 Apr 1;79(4):e51-2. https://doi.org/10.1016/j.urology.2011.08.004

10. Paul PG, Aggarwal S, Patil A. Bladder leiomyoma mimicking cervical or vaginal myoma. Gynecological Surgery. 2011 Sep;8(3):377-9. https://doi.org/10.1007/s10397-010-0608-x

11.Shim S, Borg CS, Majeed HG, Humaidan P. Paraurethral leiomyoma in a postmenopausal woman: first European case. Case reports in obstetrics and gynecology. 2015 Mar 24;2015 1-3. https://doi.org/10.1155/2015/542963

12.Dhaliwal LK, Das I, Gopalan S. Recurrent leiomyoma of the vagina. International Journal of Gynecology \& Obstetrics. 1992 Mar 1;37(4):281-3. https://doi.org/10.1016/00207292(92)90330-I 